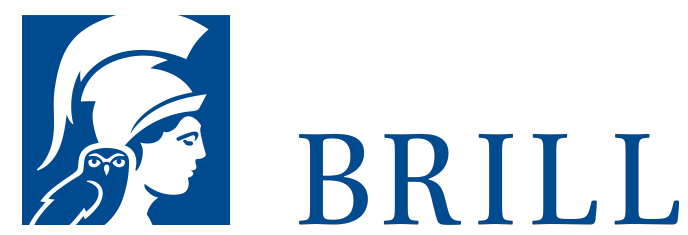

\title{
Insel(n) im Archipel
}

Zur Verwendung einer Raumfigur in den zeitgenössischen anglo-, franko- und hispanophonen Literaturen der Karibik

Author: Daniel Graziadei

Wie entstehen aus Buchstaben Inseln und Archipele? Wie steht es um diese Verbindungen aus Wasser und Land in zeitgenössischen literarischen Werken der Karibik? Können sie den kolonialen und touristischen Blick überwinden, der die Insel als Sehnsuchtsort begehrt und mit den paradoxen Qualitäten totaler Abgeschiedenheit und leicht zugänglicher Verfügbarkeit belegt?

Insel(n) im Archipel untersucht die Verwendung der regionalen Geographie in karibischen Kulturtheorien, verknüpft diese mit den Erkenntnissen der Island Studies, der Geopoetik sowie der Raumtheorie und entwickelt hieraus Fragen zur literarischen Erzeugung von Inseln und Archipelen. Beantwortet werden diese durch besonders Insel-affine Werke der karibischen Literaturen in englischer, französischer und spanischer Sprache. In seinen Analysen konzentriert sich Daniel Graziadei auf einen Publikationszeitraum von zwanzig Jahren und beginnt 1992: mit dem kontrovers diskutierten fünfhundertjährigen Jubiläum der Beschreibung oder Erfindung karibischer Inseln durch Kolumbus. Dabei führt die literaturwissenschaftliche Studie von der einsamen Insel bis zu erd- und weltweiten Verbindungen und untersucht hierbei das Kontinuum zwischen Isolation und Relation in seinen poetischen, kulturellen und intertextuellen Dimensionen.

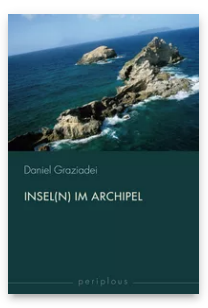

Pages: 395

Seiten

Language:

German

Subjects:

General,

Literature and

Cultural Studies

Publisher: Brill |

Fink

Series:

Periplous,

Münchener Studien zur

Literaturwissenschaft

E-Book (PDF)

Released online: 16 Sep 2019

ISBN: 978-3-

8467-618o-9

List price

Paperback

Publication date:

11 Aug 2017

ISBN: 978-3-

7705-6180-3

List price 
For more information see brill.com

Order information: Order online at brill.com +44330 333 0049 | customerservices@brill.com Submission information: brill.com/authors

Titles published by Brill | Fink, Brill | mentis or Brill | Schöningh: +49(o)715413279216| brill@brocom.de 